\title{
Estimation of shallow $S$-wave velocity structure in the Puli basin, Taiwan, using array measurements of microtremors
}

\author{
Cheng-Feng Wu and Huey-Chu Huang \\ Department of Earth and Environmental Sciences, National Chung Cheng University, Ming-Hsiung, Chia-Yi, Taiwan, R.O.C.
}

(Received May 30, 2011; Revised December 3, 2011; Accepted December 20, 2011; Online published June 28, 2012)

\begin{abstract}
The September 21, 1999, Chi-Chi earthquake induced strong shaking, resulting in severe damage in the Puli area. According to Huang and Tarng (2005), the collapse of many structures during the earthquake was very closely related to site effects. Shallow shear-wave velocities are widely used for earthquake ground-motion site characterization. Thus, we investigate $S$-wave velocity structures for the Puli area by performing microtremor array measurements at 16 sites. Dispersion curves at these sites are calculated using the F-K method (Capon, 1969) for the vertical component; $S$-wave velocity structures for the Puli area are then estimated by surface wave inversion (Herrmann, 1991). If the $S$-wave velocity of the bedrock is assumed to be $2000 \mathrm{~m} / \mathrm{s}$, the depths of the Quaternary sediments in the Puli area are between $300 \mathrm{~m}$ (FAL, PIP) and $870 \mathrm{~m}$ (DAH). Moreover, there are $3 \sim 6$ distinct interfaces in the shallow velocity structure $(0 \sim 1000 \mathrm{~m})$. The depth of the bedrock gradually increases from the edge (SIN, PIP) to the center (PUL, DAH) of the basin and the thickest Quaternary sediments appear near Heng-Chih-Cheng (DAH).
\end{abstract}

Key words: F-K method, inversion, microtremor array measurement, Puli area, site effect, $S$-wave velocity structure.

\section{Introduction}

The $S$-wave velocity is a very important factor in theoretical simulations and ground motion predictions. It is now largely obtained using well-logging which is a timeconsuming and costly method. Compared to the direct borehole method, non-intrusive surface methods (e.g. conventional exploration methods and microtremor array measurements) are considerably less expensive for obtaining shallow velocity structures. A number of studies have inverted surface-wave phase velocities, obtained from microtremor recordings, to derive near-surface material properties (Horike, 1985; Matsushima and Okada, 1990; Satoh et al., 2001a, b). However, methods reliant on microtremor data to assess site effects are still the subject of debate amongst many geophysics research groups. A research project (Site EffectS assessment using AMbient Excitations (SESAME), 2001-2004) was nanced by the European Community to assess site effects using microtremor-based techniques for seismic risk mitigation, especially in urban areas. One of its main functions was to clarify the composition and characteristics of microtremor behavior, and to investigate the analytical capacities of different microtremorbased techniques for obtaining a quantitative description of site features, by analyzing and comparing observational data with simulations. Kind et al. (2005) applied the highresolution beamforming method to derive phase velocities from ambient vibrations. Tests with synthetic ambient vi-

Copyright (C) The Society of Geomagnetism and Earth, Planetary and Space Sciences (SGEPSS); The Seismological Society of Japan; The Volcanological Society of Japan; The Geodetic Society of Japan; The Japanese Society for Planetary Sciences; TERRAPUB.

doi:10.5047/eps.2011.12.002 brations con rm the capability of the method to extract the correct phase velocities of the excited Rayleigh mode. The inverted $S$-wave velocity structure corresponds well to data from an $S$-wave re ection survey and the geological information for two measurement sites. Di Giulio et al. (2006) deployed ve small-aperture array measurements of microtremors to study wave- eld properties and shallow velocity structures in the Col orito plain, Italy. They pointed out that the vertical and horizontal components of the microtremor signals were dominated by Rayleigh waves and Love waves (Arai and Tokimatsu, 2000), respectively. The inverted shear-wave velocity pro les are consistent with $a$ priori information for four different sites that can be approximated by a simplistic 1D model. Maresca et al. (2006) analyzed the ambient noise recorded in the Col orito Basin, Italy, using $H / V$ spectral ratios and array techniques. They correlated the frequency variation with the structure of the basin, investigated the directional properties of the noise wave eld and recognized the possible in uence of the basin structure on the propagation of seismic waves. Huang and $\mathrm{Wu}$ (2006) performed microtremor array measurements for a total of 28 arrays at seven sites to estimate the $S$-wave velocity structures in Chia-Yi City. According to the $f-k$ analysis, at frequencies lower than about $1 \mathrm{~Hz}$, the generation of microtremors may be attributed to the ocean waves of the Taiwan Strait. Based on the inverted results, the alluvial layer of the city is about $1000 \sim 1200 \mathrm{~m}$ thick if the $S$-wave velocity of the bedrock is assumed to be $1,500 \mathrm{~m} / \mathrm{s}$. The depth of the alluvium gradually increases from the east to the west and from the north to the south.

The Chi-Chi earthquake $\left(M_{\mathrm{L}} 7.3\right)$ occurred on September 21, 1999, in the Nantou prefecture of central Tai- 


\section{GEOLOGICAL MAP}

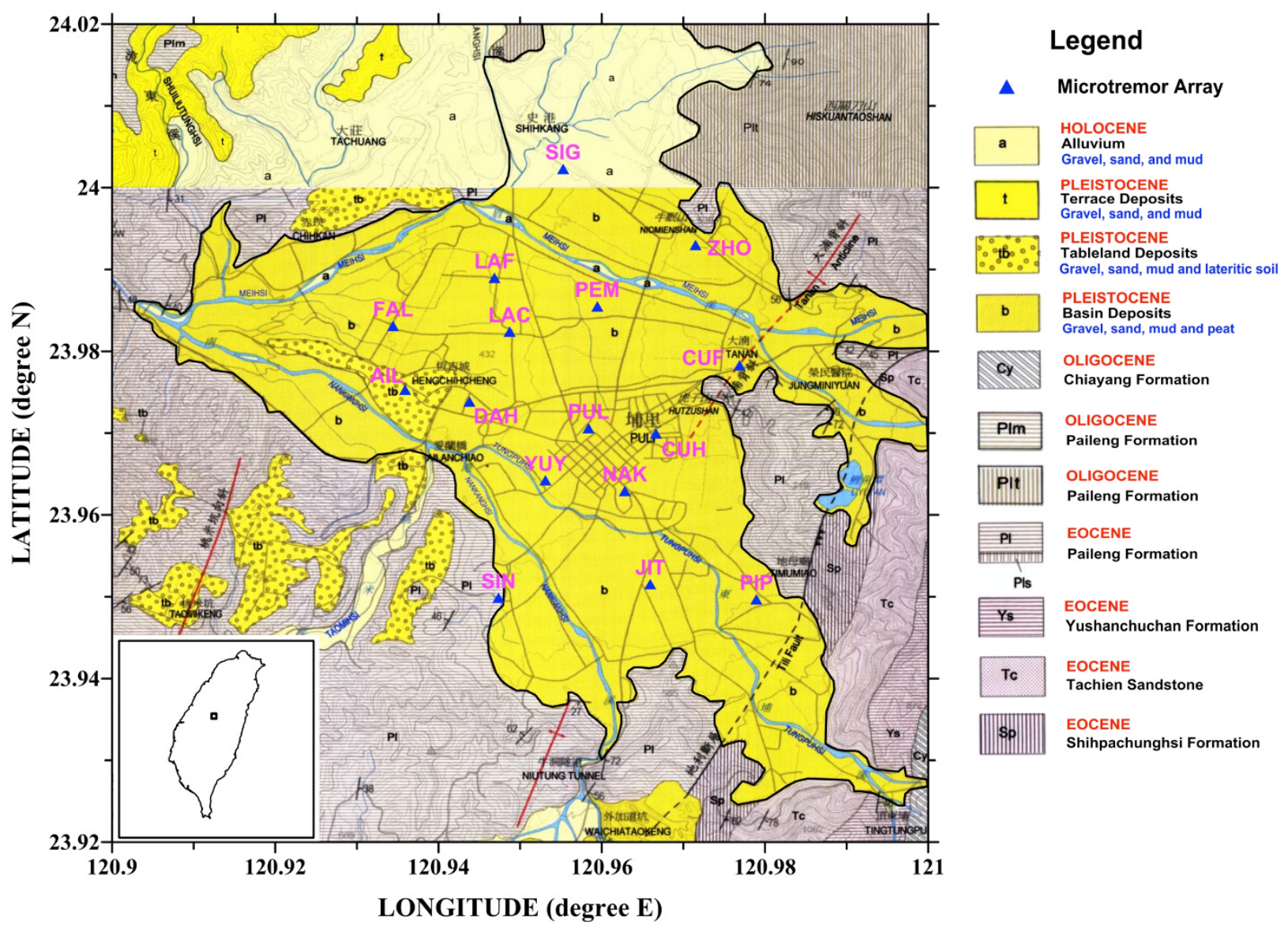

Fig. 1. Geological map of Puli area superimposed with the 16 used sites. Triangles denote the sites of the microtremor array measurements (modified from Huang et al., 2000).

wan. The mainshock and subsequent aftershocks destroyed over 8,500 buildings and seriously damaged another 6,200 . Damage was heaviest in the central Taiwan counties (Taichung, Nantou, and Yunlin). In the central mountain city of Puli, large ground shaking caused devastating effects in the center of the town, with many buildings either being seriously damaged or totally collapsed. In order to investigate the site characterization of the Puli area, Huang and Tarng (2005) carried out dense microtremor measurements at 87 sites inside the basin. They concluded that the building damage during the Chi-Chi earthquake was very closely related to site effects in Puli.

Owing to a lack of drilling and geophysical data, many ambiguities still exist about the underground structure. In this study, therefore, we conduct microtremor array measurements at 16 sites to explore shallow $S$-wave velocity structures and the depths of bedrock in the Puli basin.

\section{Sites and Data}

The Puli area is located in central Taiwan. Figure 1 shows the geological map of the Puli area. In topography, Puli is a structural basin which is the downcast area of a Tertiary submetamorphic rock mountain. In the southwest and in the northern boundary zone of the Puli basin, stream terraces are found. In the western part of the Puli basin, flat smooth hills and spacious valleys which have suffered from strong weathering predominate. The surface of the layers is covered with laterite. Inside the Puli basin, except for some sections which are terrace deposits and river alluvium, most sections are basin deposits. At a depth of $50 \mathrm{~m}$ in the Meihsi and the Nankanhsi, most rocks are composed of conglomerates, which, in their thickest parts, often exceed $100 \mathrm{~m}$ in depth. The basin is mostly comprised of recent alluvium which, from the top down, can be divided into five sublayers (Huang et al., 2000): (a) alluvium; (b) tableland deposit conglomerate; (c) Toukoshan formation conglomerate; (d) Toukoshan formation clay; and (e) Tertiary basement.

The basic geophysical aspects for understanding seismic response in the Puli basin are its bedrock geometry and $P$-wave and $S$-wave velocity distribution. Wang et al. (2003) studied the shallow velocity structures of the northern part of the Puli basin using the shallow seismic reflection method. Their results showed that the largest depth of the bedrock is about $500 \mathrm{~m}$, and the shape of bedrock in the Puli basin is roughly symmetrically concave. In order to explain the forms of the Tertiary basement and the Quaternary formations of the basin, Huang (2008) used a high-resolution shallow seismic reflection method in combination with the results of Wang et al. (2003). After careful combination of both sets of results, Huang (2008) proposed the following conclusions: (1) the deepest part of the basement of the Puli basin does not exceed $600 \mathrm{~m}$, and the west- 


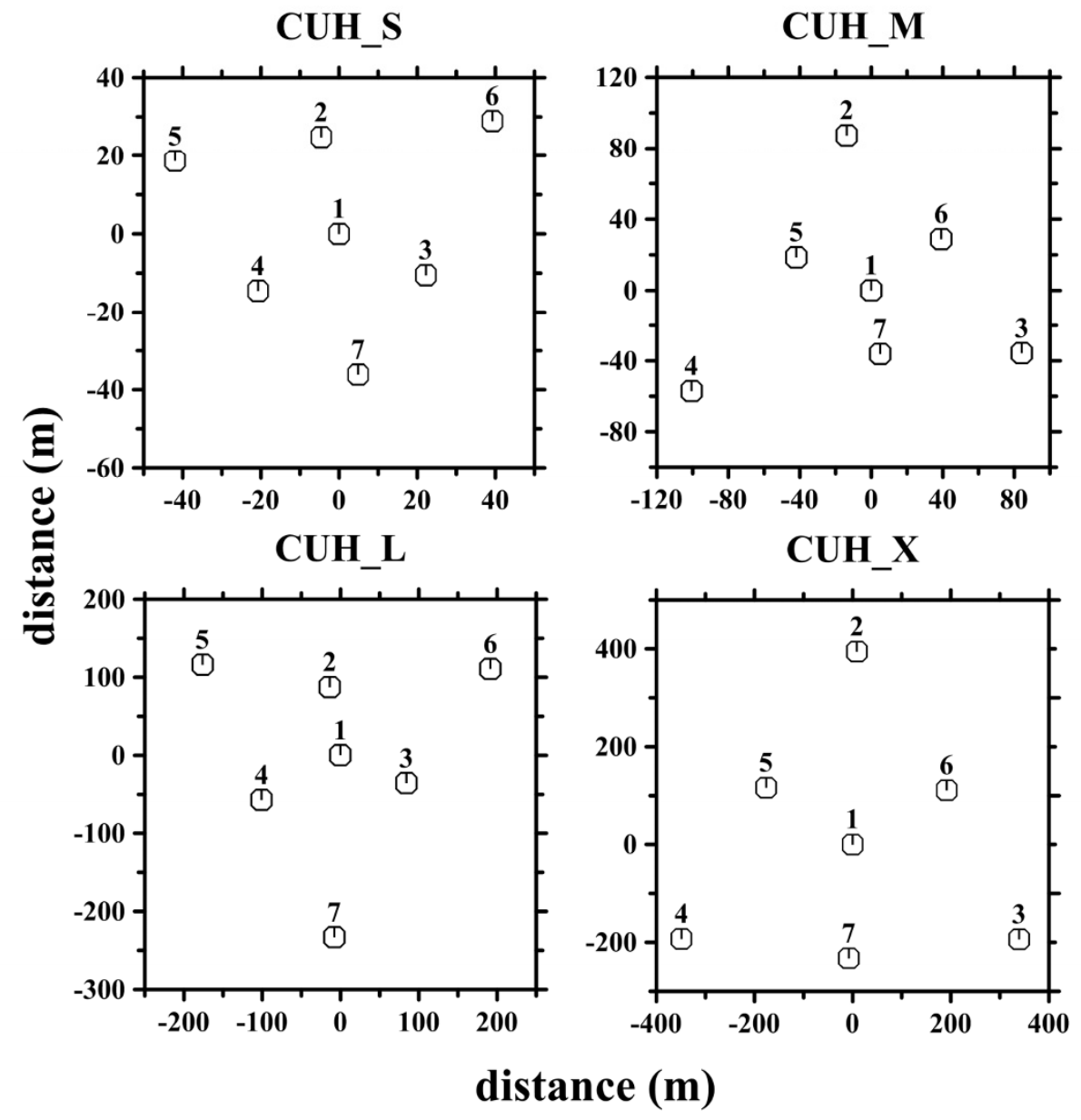

Fig. 2. Array con gurations of S-, M-, L- and X-arrays at the CUH site.

ern portion is deeper. The top $100 \mathrm{~m}$ of basin sediment is dominantly gravel and the deeper part, sand and mud. (2) $P$-wave velocity of the Quarternary sediments in the basin is $2200 \mathrm{~m} / \mathrm{s}$, and $S$-wave velocity is $950 \mathrm{~m} / \mathrm{s}$. On the other hand, $P$-wave velocity of the basement rock is $4300 \mathrm{~m} / \mathrm{s}$ and $S$-wave velocity, $2000 \mathrm{~m} / \mathrm{s}$. (3) The basement rock belongs to the pre-Tertiary Paileng formation. (4) Sediment layers within the basin are not at, and have apparent dipping angles. (5) No apparent faults have been discovered in the basin. (6) Down warping may have been the dominant formation mechanism during the basin's early history; however, in its later stages, formation has been controlled by river erosion.

Array measurements of microtremors were carried out at 16 sites, as shown in Fig. 1. We used seven observation points in each array deployment and four array measurements of different size (S, M, L and X) at each site. Here, we take site CUH as an example. Figure 2 shows the array con gurations in the $\mathrm{S}, \mathrm{M}, \mathrm{L}$ and $\mathrm{X}$ sizes at the site. The central station (No. 1) is xed for all of the arrays which are $S$ (radius $=50 \mathrm{~m}), M$ (radius $=100 \mathrm{~m}$ ), $\mathrm{L}$ (radius $=200 \mathrm{~m}$ ) and $\mathrm{X}$ (radius $=400 \mathrm{~m}$ ) arrays. The con guration of these seven stations is in the form of two different-aperture triangles around the central station. However, the regular triangular shape of the array is often distorted by roads, buildings or structures. The locations and array sizes, and the maximum and minimum separations of instruments for the 16 sites are tabulated in Table 1. The vertical component of the velocity waveforms of the $S$ array at site CUH is shown in Fig. 3. In general, the waveforms are similar to each other, especially at the stations closest to one another.

Array measurements of microtremors were performed using seven sets of portable instruments. Each set of instruments includes a tri-axial servo velocity sensor (VSE315D), an ampli er, and a 24-bit analog-to-digital recorder (SAMTAC-801B). This velocity sensor has a at amplitude response from 0.1 to $70 \mathrm{~Hz}$. The accuracy of the internal clock is within $1 \mathrm{ppm}$ and is corrected by the Global Positioning System (GPS) before each measurement. The timing accuracy from GPS correction is within $1 \mathrm{~ms}$. The positions of the sensors are determined using Trimble's GPS Path nder System receivers, that provide real-time submeter accuracy. At each observation point, microtremor data was continuously recorded for about 68 minutes during the day time at a sampling frequency of $200 \mathrm{~Hz}$.

\section{Methods of Analysis}

\subsection{F-K spectral analysis method}

The technique we use in this study for data analysis is the maximum likelihood method (MLM) proposed by Capon (1969). This method uses the cross-power spectral densities 
Table 1. Array locations, sizes, maximum and minimum separations between instruments for 16 sites.

\begin{tabular}{|c|c|c|c|c|c|}
\hline Site name & $\begin{array}{l}\text { Latitude } \\
\text { (degree) }\end{array}$ & $\begin{array}{l}\text { Longitude } \\
\text { (degree) }\end{array}$ & Size & $\begin{array}{c}\text { Min. separation } \\
\text { (m) }\end{array}$ & $\begin{array}{c}\text { Max. separation } \\
\text { (m) }\end{array}$ \\
\hline \multirow{4}{*}{ AIL } & \multirow{4}{*}{23.975} & \multirow{4}{*}{120.936} & $S$ & 24.0 & 88.1 \\
\hline & & & $\mathrm{M}$ & 50.4 & 198.2 \\
\hline & & & $\mathrm{L}$ & 103.1 & 344.6 \\
\hline & & & $\mathrm{X}$ & 184.8 & 711.5 \\
\hline \multirow{4}{*}{ CUF } & \multirow{4}{*}{23.978} & \multirow{4}{*}{120.977} & $S$ & 24.5 & 96.3 \\
\hline & & & $\mathrm{M}$ & 49.5 & 178.1 \\
\hline & & & $\mathrm{L}$ & 96.6 & 387.1 \\
\hline & & & $\mathrm{X}$ & 201.0 & 745.4 \\
\hline \multirow{4}{*}{ CUH } & \multirow{4}{*}{23.970} & \multirow{4}{*}{120.967} & $S$ & 24.6 & 81.9 \\
\hline & & & $\mathrm{M}$ & 36.4 & 186.2 \\
\hline & & & $\mathrm{L}$ & 88.5 & 397.5 \\
\hline & & & $X$ & 211.3 & 688.0 \\
\hline \multirow{4}{*}{ DAH } & \multirow{4}{*}{23.974} & \multirow{4}{*}{120.944} & $\mathrm{~S}$ & 24.2 & 90.5 \\
\hline & & & $\mathrm{M}$ & 47.1 & 187.1 \\
\hline & & & $\mathrm{L}$ & 100.4 & 350.2 \\
\hline & & & $\mathrm{X}$ & 189.8 & 709.3 \\
\hline \multirow{4}{*}{ FAL } & \multirow{4}{*}{23.983} & \multirow{4}{*}{120.934} & $\mathrm{~S}$ & 24.1 & 89.0 \\
\hline & & & $\mathrm{M}$ & 48.5 & 185.8 \\
\hline & & & $\mathrm{L}$ & 97.6 & 384.6 \\
\hline & & & $X$ & 198.0 & 731.1 \\
\hline \multirow{4}{*}{ JIT } & \multirow{4}{*}{23.951} & \multirow{4}{*}{120.966} & $\mathrm{~S}$ & 23.9 & 93.8 \\
\hline & & & $\mathrm{M}$ & 47.5 & 174.7 \\
\hline & & & $\mathrm{L}$ & 97.9 & 347.7 \\
\hline & & & $X$ & 196.1 & 708.6 \\
\hline & & & $\mathrm{S}$ & 18.7 & 89.7 \\
\hline $\mathrm{J} A \mathrm{C}$ & 23082 & 120949 & M & 47.4 & 173.3 \\
\hline LAC & 23.982 & 120.949 & $\mathrm{~L}$ & 92.5 & 363.1 \\
\hline & & & $\mathrm{X}$ & 196.9 & 714.6 \\
\hline & & & $\mathrm{S}$ & 24.4 & 91.1 \\
\hline $\mathrm{I} A \mathrm{~F}$ & 23080 & 120947 & $\mathrm{M}$ & 49.5 & 190.5 \\
\hline LAF & 25.989 & $120.94 /$ & $\mathrm{L}$ & 100.3 & 343.1 \\
\hline & & & $\mathrm{X}$ & 186.8 & 705.4 \\
\hline & & & $\mathrm{S}$ & 24.3 & 98.4 \\
\hline & & & $\mathrm{M}$ & 48.4 & 172.8 \\
\hline NAK & 23.963 & 120.963 & $\mathrm{~L}$ & 97.3 & 373.7 \\
\hline & & & $\mathrm{X}$ & 210.1 & 718.9 \\
\hline & & & $\mathrm{S}$ & 20.3 & 80.2 \\
\hline PFM & 23085 & 120050 & $\mathrm{M}$ & 41.9 & 173.8 \\
\hline PEIM & 23.985 & 120.959 & $\mathrm{~L}$ & 98.3 & 363.3 \\
\hline & & & $\mathrm{X}$ & 200.5 & 732.2 \\
\hline & & & $\mathrm{S}$ & 24.3 & 88.3 \\
\hline PIP & 23949 & 120979 & $\mathrm{M}$ & 48.3 & 187.9 \\
\hline PIP & 23.949 & 120.979 & $\mathrm{~L}$ & 97.0 & 350.4 \\
\hline & & & $\mathrm{X}$ & 194.1 & 718.3 \\
\hline & & & $\mathrm{S}$ & 22.5 & 97.0 \\
\hline PUI & 23970 & 120958 & $\mathrm{M}$ & 51.5 & 169.3 \\
\hline PUL & 25.910 & 120.958 & $\mathrm{~L}$ & 74.9 & 359.0 \\
\hline & & & $\mathrm{X}$ & 194.3 & 693.8 \\
\hline & & & $\mathrm{S}$ & 17.6 & 92.9 \\
\hline SIG & 24.002 & 120955 & $\mathrm{M}$ & 50.9 & 198.1 \\
\hline SIG & 24.002 & 120.955 & $\mathrm{~L}$ & 85.2 & 344.1 \\
\hline & & & $\mathrm{X}$ & 190.7 & 694.4 \\
\hline & & & $S$ & 15.6 & 70.5 \\
\hline & & & $\mathrm{M}$ & 37.5 & 166.3 \\
\hline SIN & 23.950 & 120.947 & $\mathrm{~L}$ & 74.3 & 363.5 \\
\hline & & & $X$ & 196.9 & 689.0 \\
\hline
\end{tabular}


Table 1. (continued).

\begin{tabular}{|c|c|c|c|c|c|}
\hline Site name & $\begin{array}{l}\text { Latitude } \\
\text { (degree) }\end{array}$ & $\begin{array}{c}\text { Longitude } \\
\text { (degree) }\end{array}$ & Size & $\begin{array}{c}\text { Min. separation } \\
\text { (m) }\end{array}$ & $\begin{array}{l}\text { Max. separation } \\
\text { (m) }\end{array}$ \\
\hline \multirow{4}{*}{ YUY } & \multirow{4}{*}{23.964} & \multirow{4}{*}{120.953} & $S$ & 24.6 & 84.4 \\
\hline & & & $M$ & 46.5 & 171.1 \\
\hline & & & $\mathrm{L}$ & 97.2 & 352.2 \\
\hline & & & $\mathrm{X}$ & 197.4 & 705.6 \\
\hline \multirow{4}{*}{$\mathrm{ZHO}$} & \multirow{4}{*}{23.993} & \multirow{4}{*}{120.971} & $S$ & 23.7 & 93.8 \\
\hline & & & M & 47.2 & 174.8 \\
\hline & & & $\mathrm{L}$ & 98.4 & 359.0 \\
\hline & & & $\mathrm{X}$ & 197.1 & 714.4 \\
\hline
\end{tabular}

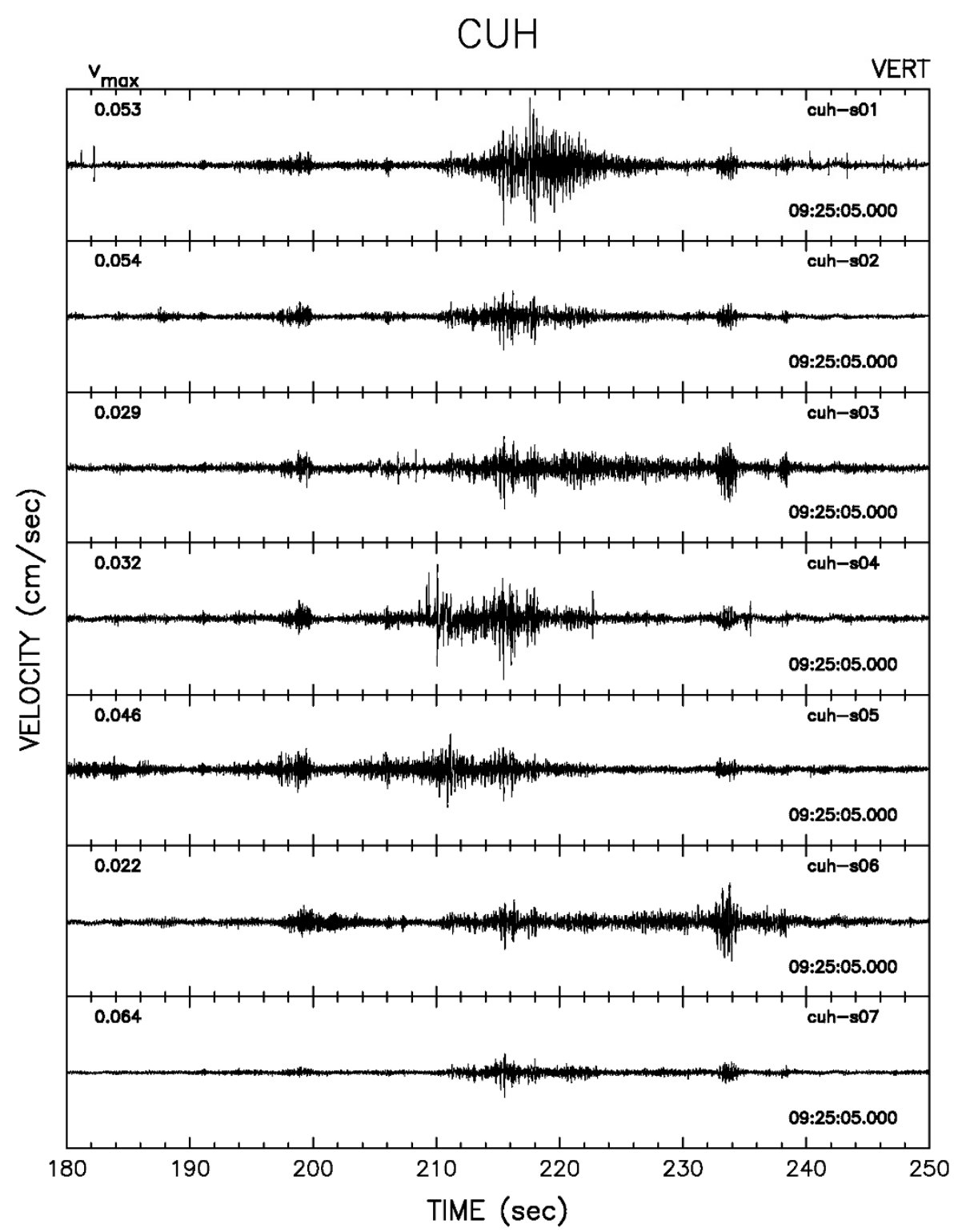

Fig. 3. Velocity records of the vertical component of one time-segment for the S array at site CUH.

of an array of $N$ sensors to estimate the $f-k$ spectrum, refining it with coherency estimates. The estimate of the $f-k$ spectrum $P(f, k)$ by MLM is given by:

$$
P(f, k)=\left[\sum_{i, j=1}^{N} \phi_{i j}^{-1}(f) \exp \left(i \vec{k} \cdot \vec{r}_{i j}\right)\right]^{-1},
$$

where $N$ is number of sensors; $\phi_{i j}(f)$ is the cross-power spectrum between the $i$ th and $j$ th sensors at frequency $f$; $\vec{r}_{i j}=\vec{r}_{j}-\vec{r}_{i}$ where $\vec{r}_{i}$ and $\vec{r}_{j}$ are the position vectors of the $i$ th and $j$ th sensors, respectively; and $\phi_{i j}^{-1}(f)$ is the element of the corresponding inverse for the matrix $\phi_{i j}(f)$.

Based on the results of the $f-k$ power spectrum, the phase 
velocity $V$ can be estimated by:

$$
V=f / \sqrt{k_{x_{0}}^{2}+k_{y_{0}}^{2}}
$$

where $k_{x_{0}}$ and $k_{y_{0}}$ correspond to the peak power positions in the wavenumber space.

\subsection{Inversion of the velocity structure}

The relationship between the dispersion curve of the surface-wave and the velocity structure is nonlinear. For convenience in structure inversion, a quasi-linear relationship between the dispersion curve and velocity structure will be retrieved through the Taylor series expansion when the high-order terms are neglected. Because the phase velocities are more sensitive to the $S$-wave velocity structure than to the $P$-wave velocity and density structures (Horike, 1985; Hwang and Yu, 2005), only the $S$-wave velocity is inverted in this study. The formula, joining the dispersion curve and velocity model parameters, can be written as follows (Hwang and $\mathrm{Yu}, 2005)$ :

$$
\Delta C\left(T_{j}\right)=\sum_{i=1}^{N}\left(\frac{\partial C\left(T_{j}\right)}{\partial \beta_{i}}\right) \Delta \beta_{i},
$$

where $\Delta C\left(T_{j}\right)$ is the difference between the observed and the predicted phase velocity derived from the initial velocity model at the $j$ th period $\left(T_{j}\right) ; N$ is the number of layers; $\partial C\left(T_{j}\right) / \partial \beta_{i}$ is the partial derivative of the phase-velocity of the $j$ th period with respect to the $S$-wave velocity of the $i$ th layer; and $\Delta \beta_{i}$ is the resulting difference in the $S$-wave velocity of the $i$ th layer between adjacent inversions.

To solve model parameters $\left(\Delta \beta_{i}\right)$ of Eq. (3), we employ a surface-wave inversion program based on damped leastsquares and developed by Herrmann (1991). Moreover, the program used here is based on the assumption that the fundamental mode of the Rayleigh wave is dominant. Smoothing constraints, the difference between adjacent model parameters as an approximation of a derivative to control solution roughness, were also used (e.g., Menke, 1984). In this study, an initial layered model at each site is rst constructed with assigned values of thickness, $S$-wave velocities, and Poisson's ratio for each layer. We take a halfspace structure with an $S$-wave velocity, which is the maximum phase velocity divided by 0.92 at the lowest frequency used, as the $S$-wave velocity in the initial model. Also, the total layer number and the thickness of each layer are designed to be 80 and $30 \mathrm{~m}$. If we are using a maximum frequency of $8 \mathrm{~Hz}$, and assuming a phase velocity of $700 \mathrm{~m} / \mathrm{s}$, the minimum expected wavelength is about $90 \mathrm{~m}$. Accordingly, by rule-of-thumb calculation, the highest resolution of thickness can be estimated as being about one-third of the observed minimum wavelength. Therefore, we expect to resolve a 30 -m-thick layer. A damping value of 1.0 is adopted to stabilize the inversion. The inversion process will be terminated when the difference in $S$-wave velocity for each layer between the adjacent inversions is less than $0.001 \mathrm{~km} / \mathrm{s}$. Although the inversion of phase velocity is non-unique, we carefully inspect the rationality of the inverted $S$-wave velocity and any mis t between observed and theoretical phase velocities for each inversion. Hence, a reasonable velocity model can be obtained. The above inversion process is the differential inversion technique (Herrmann, 1991).

In the study, the total layer number is designed to be 80 for the differential inversion. Because the layer number is too great, the inverted structure is not suitable to enable ground motion simulation in the future. Therefore, in addition, we use a stochastic inversion technique. First, based on the differential inverted result, we regroup the layered structure. On the basis of the gradient changes in the differential inverted results, we are able to determine the boundaries between the layers. The inverted structure with 80 layers is simpli ed to be a structure with fewer layers. Secondly, we choose the simpli ed structure as the initial model and then invert the structure using the stochastic inversion technique. During the stochastic inversion process, the parameters (e.g. velocity and thickness) between layers are independent. Besides, the damping value and the termination condition of the program used are the same with the differential inversion technique.

\section{Results and Discussions}

\subsection{F-K analysis of microtremor array data}

We divide the observed recordings of the vertical component into time segments with a length of $20.48 \mathrm{~s}$ for the $\mathrm{S}$ - and M-array recordings, and $40.96 \mathrm{~s}$ for the L- and Xarray recordings, by overlapping one-half of each window length. After removing the time segment contaminated by instrumental or arti cial noise, we estimate phase velocities by $f-k$ spectral analysis based on the Maximum Likelihood Method (MLM) (Capon, 1969). The maximum wavenumber set in the $f-k$ spectrum is derived theoretically from the effective Nyquist wavenumber that refers to the reciprocal of twice the minimum station separation (Table 1). Figure 4 shows the $f-k$ spectra from the MLM using the microtremor data observed at the site CUH. We calculate the $f-k$ spectra at $51 \times 51$ grid points at each frequency. This gure presents the $f-k$ spectra at $5.76 \mathrm{~Hz}, 3.81 \mathrm{~Hz}$, $2.25 \mathrm{~Hz}$ and $0.88 \mathrm{~Hz}$ from the records observed by the S-, $\mathrm{M}-$, L- and X-arrays, respectively. The propagation direction $(\theta)$ is measured clockwise from the north in degrees. We estimate the phase velocity $(V)$ in $\mathrm{km} / \mathrm{s}$ from the maximum peak in the $f-k$ spectrum. Since we search the maximum peaks within the wavenumber windows that we set a priori, the minimum phase velocities are limited, but the maximum ones are not.

Figure 5 shows the propagation directions we estimate from all the selected $f-k$ spectra for the: (a) S-array, (b) Marray, (c) L-array, and (d) X-array, at the site CUH. The original numbers of time segments for the $f-k$ spectra calculations at the CUH site are 385, 385, 189 and 189 for the S-, M-, L- and X-arrays, respectively. After removing the time segments contaminated by instrumental or arti cial noise and excluding the unreliable phase velocity data, the nal time segments used in Fig. 5 are 380, 377, 179 and 99 for the S-, M-, L- and X-arrays, respectively. At frequencies lower than about $0.66 \mathrm{~Hz}$, the propagation directions are concentrated in the northwest and west quadrants, which coincide with the direction of the coastal line of the Taiwan Strait. At frequencies higher than about $5 \mathrm{~Hz}$, the propagation directions are concentrated in the east-northeast. At 

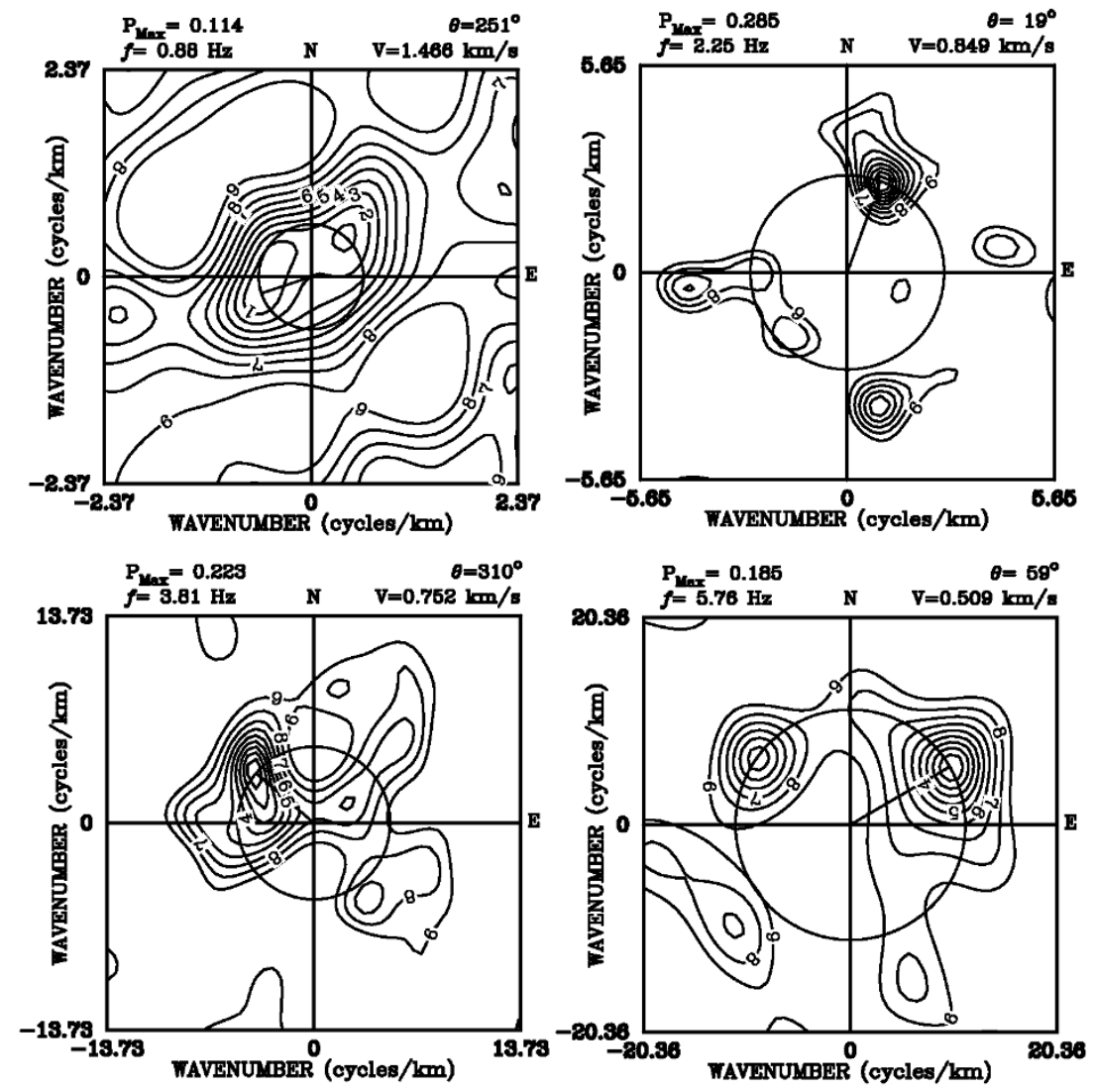

Fig. 4. The $f-k$ spectra plot of four different frequencies: $0.88,2.25,3.81$, and $5.76 \mathrm{~Hz}$ are calculated from microtremors records observed by $\mathrm{X}, \mathrm{L}$, M, and $\mathrm{S}$ arrays, respectively, at site CUH.
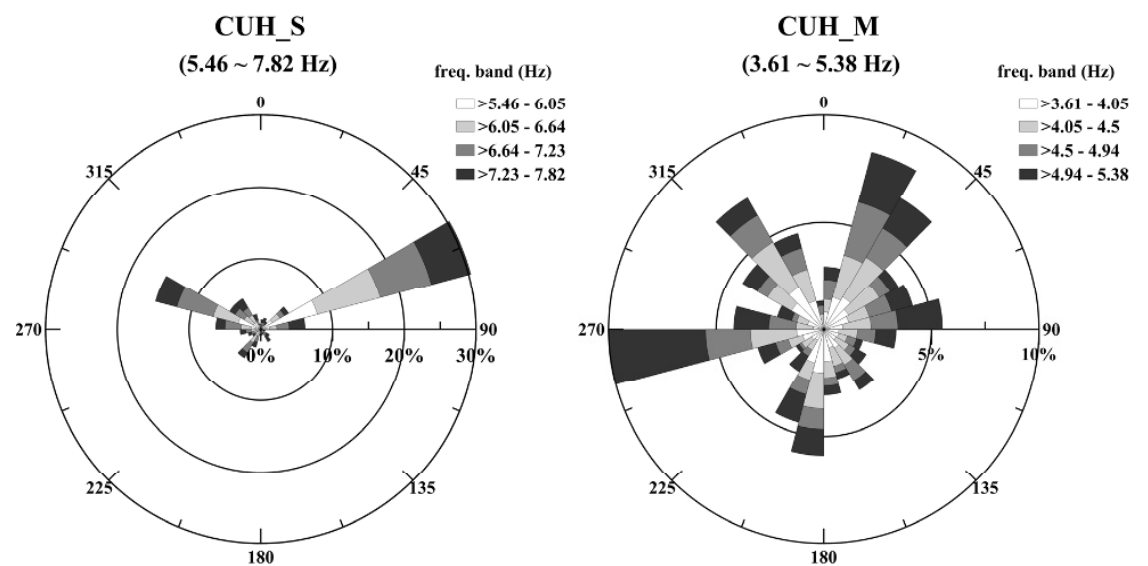

CUH_L
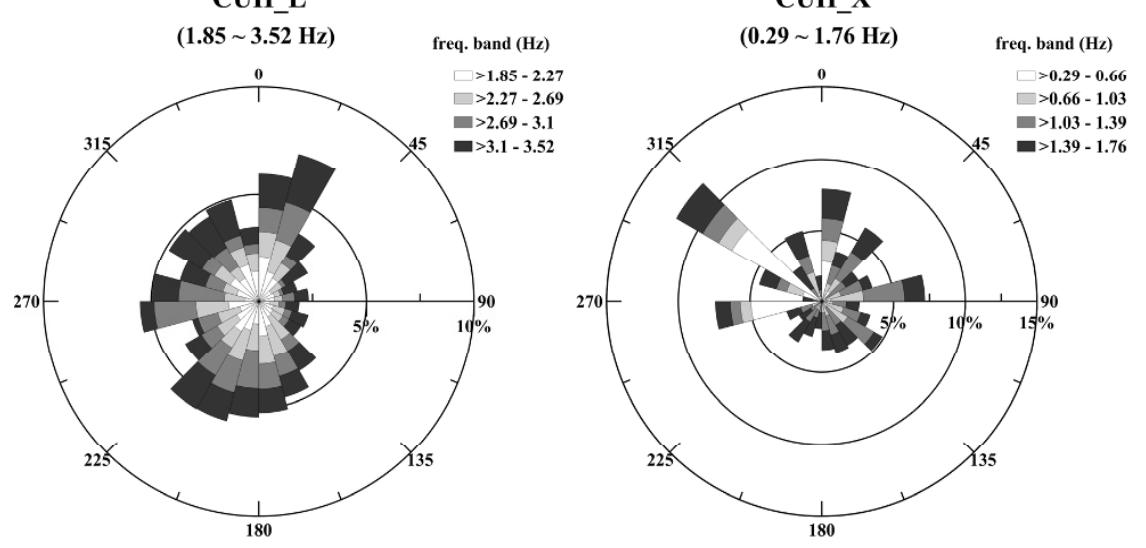

Fig. 5. Propagation directions estimated from all the $f-k$ spectra for $\mathrm{S}, \mathrm{M}, \mathrm{L}$, and $\mathrm{X}$ arrays at site CUH. 


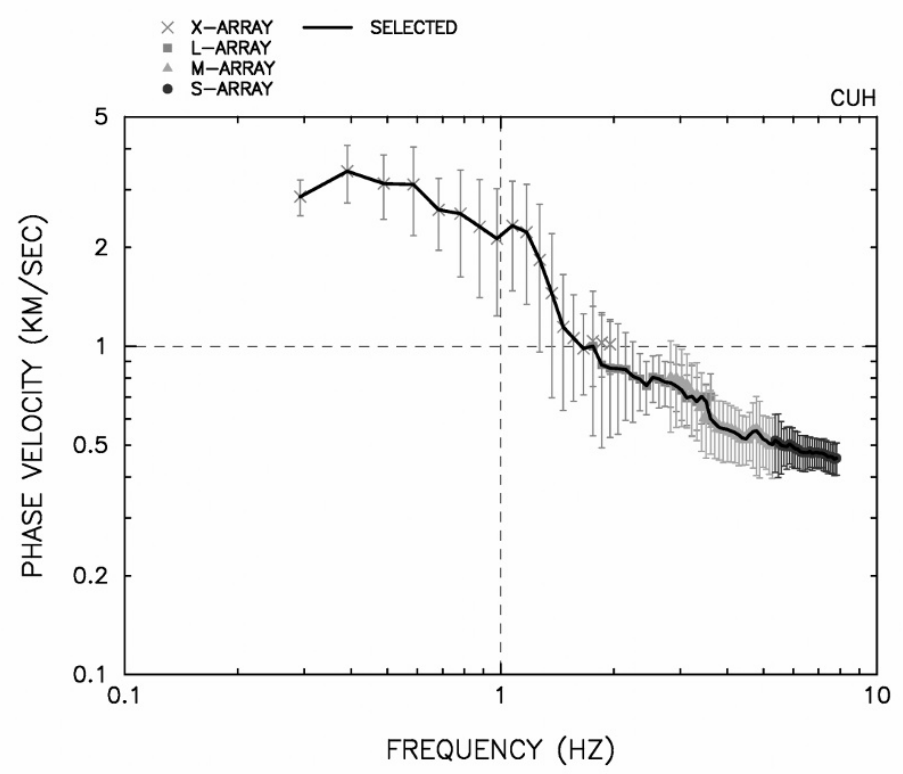

Fig. 6. Phase velocities obtained from recordings observed at site CUH. The vertical lines indicate \pm 1 standard deviation of the average phase velocity values. Different symbols represent the results from the different size arrays. The black line represents the selected dispersion curve at site CUH.
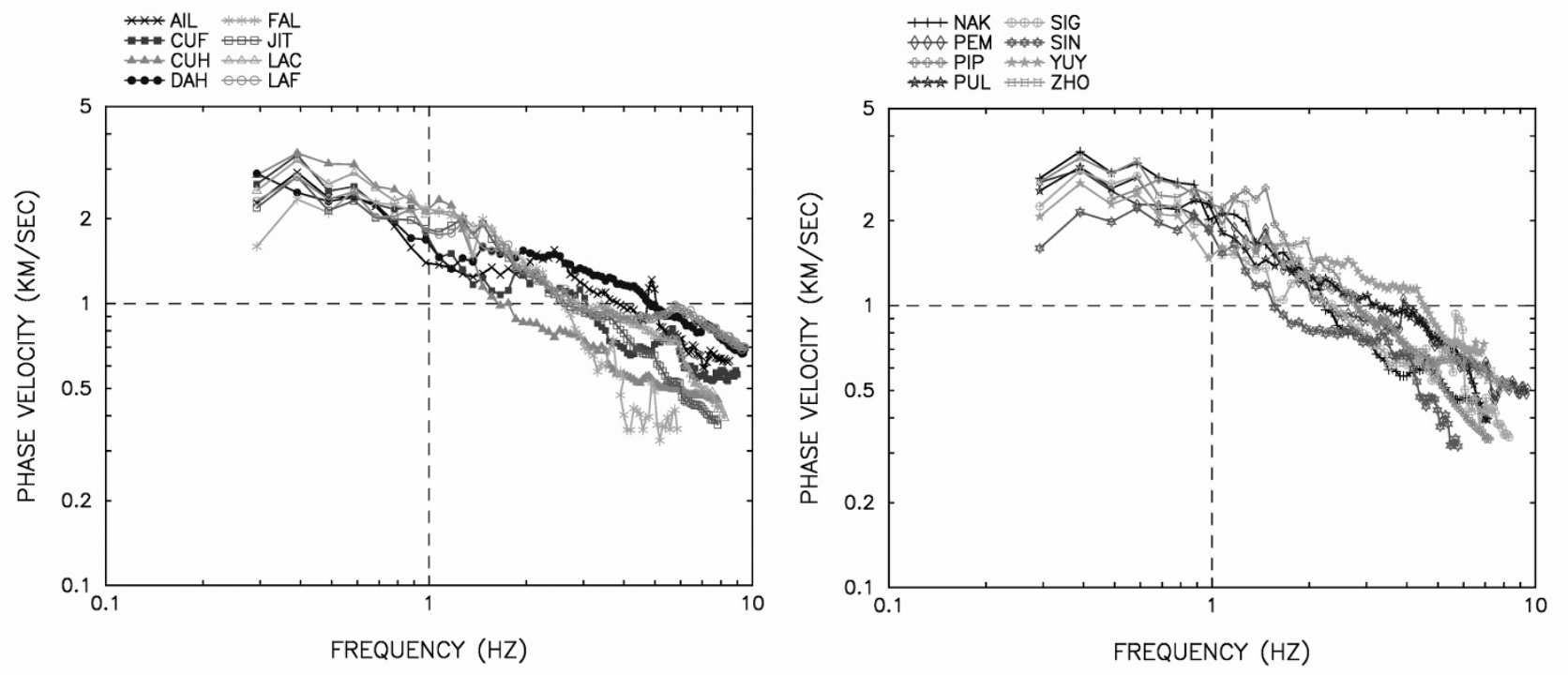

Fig. 7. Phase velocities obtained from recordings observed at all 16 sites. It is divided into two panels because the lines are too numerous for one gure.

frequencies between about 1 and $5 \mathrm{~Hz}$, however, propagation directions are relatively scattered. Through on-site inspections, this result is consistent with traf c sources and human activity.

The phase velocity can be estimated from the frequency and the wavenumber of the maximum peak in the $f-k$ spectrum. Since the phase velocity of the Rayleigh wave is less than the $S$-wave velocity, we set the upper threshold of the phase velocity as $4.5 \mathrm{~km} / \mathrm{s}$. Moreover, we also searched maximum $\left(C_{\max }\right)$ and minimum $\left(C_{\min }\right)$ phase velocities for each frequency and exclude unreliable phase velocities with a signi cance level of $5 \%$ of $\left(C_{\max }-C_{\min }\right)$. We then choose a value by taking an average over the reliable phase velocities. The averages and averages \pm 1 standard deviation of the phase velocities obtained from the recordings at site CUH are shown in Fig. 6. The different symbols represent the results from the different size arrays. When valid frequency ranges of phase velocities obtained from two different arrays (e.g. X and L arrays) overlap, we choose one connecting frequency among the overlapping frequencies and take the average of the two phase velocities at that frequency. In the frequency range lower than this connecting frequency, we select phase velocities obtained from the larger size array (e.g. X array), and in the higher frequency range, we select phase velocities obtained from the smaller size array (e.g. L array). The nal phase velocities (the solid line in Fig. 6) are chosen by following the sequence of the $\mathrm{X}-(0.3 \mathrm{~Hz} \leq f<1.7 \mathrm{~Hz})$, L$(1.7 \mathrm{~Hz} \leq f<3.5 \mathrm{~Hz}), \mathrm{M}-(3.5 \mathrm{~Hz} \leq f<5.3 \mathrm{~Hz})$ and $\mathrm{S}$ array $(5.3 \mathrm{~Hz} \leq f \leq 7.8 \mathrm{~Hz})$ from low frequencies to high frequencies. Basically, the results of the X-and L-arrays are stable at lower frequencies, whereas those of the S- and 


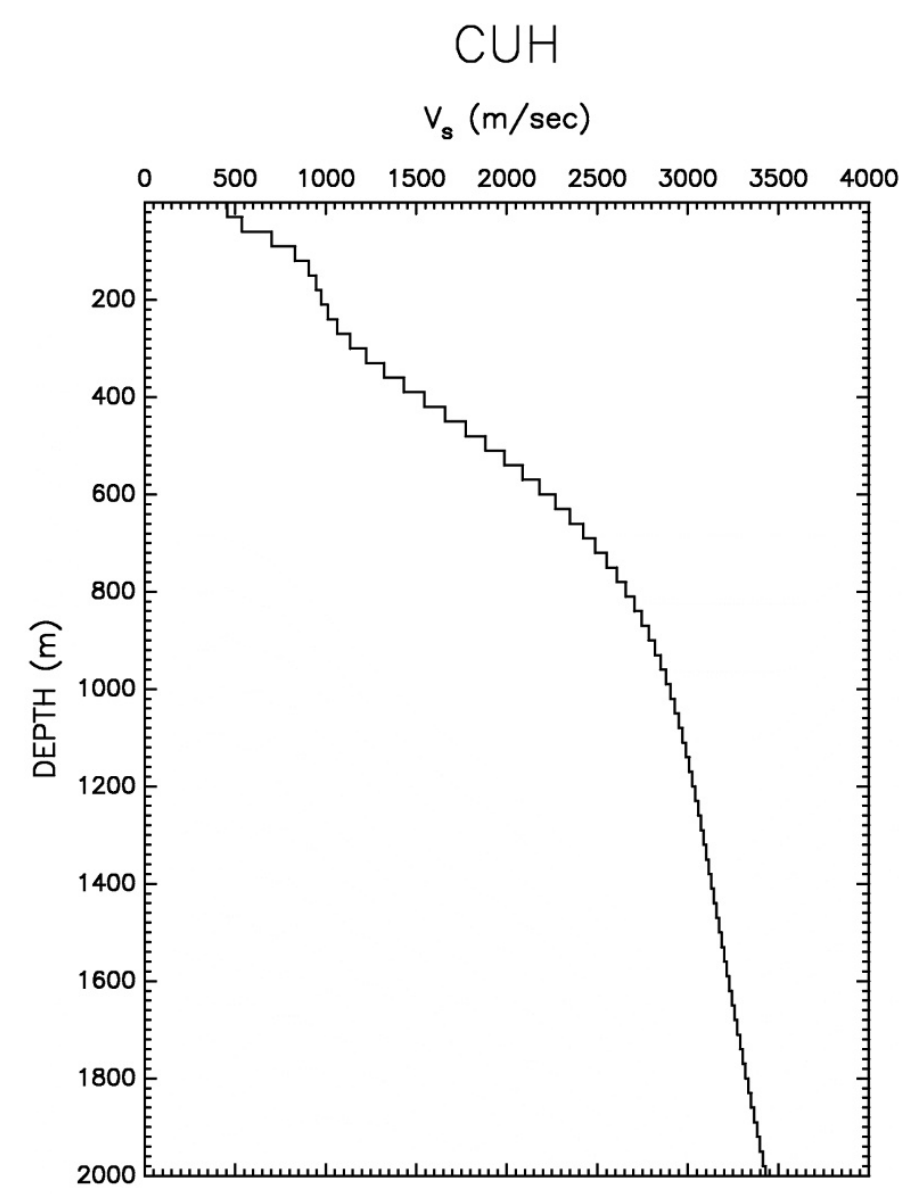

Fig. 8. Estimated $S$-wave velocity structures by the differential inversion technique at site CUH.

M-arrays are stable at higher frequencies.

Figure 7 shows the phase velocities obtained from the recordings observed at all 16 sites. The estimated phase velocities vary from site to site. Sites AIL, DAH, and YUY have higher phase velocities than FAL and SIN while the frequencies are greater than $3 \mathrm{~Hz}$. It indicates that sites AIL, DAH and YUY have higher $S$-wave velocities at the near-surface shallow structures. In addition, at these three sites (AIL, DAH and YUY), the observed phase velocities become rather at between frequencies 1.0 and $2.7 \mathrm{~Hz}$ with phase velocities of about $1.3-1.5 \mathrm{~km} / \mathrm{s}$. These results suggest that a thicker layer with an $S$-wave velocity of about $1.4-1.6 \mathrm{~km} / \mathrm{s}$ was deposited at these sites.

\subsection{Inversion of the $S$-wave velocity structures}

We rst invert $S$-wave velocity structures using the differential inversion technique (Herrmann, 1991). Based on Fig. 6, the shallow $S$-wave velocity structure at site CUH is shown in Fig. 8. As stated previously, the total layer number is 80 and the thickness of each layer is $30 \mathrm{~m}$. We only show the results for depths of $0 \sim 2000 \mathrm{~m}$ here. In order to demonstrate the validity of the inverted velocity structure, we compare the theoretical phase velocities of the fundamental mode of the Rayleigh wave for the inverted structure (solid line) with the observed phase velocities (open circles) in Fig. 9. The dashed line represents the initial model for the inversion. We take a half-space structure with an $S$-wave velocity which is the maximum phase velocity divided by
0.92 at the used lower frequency as the $S$-wave velocity in the initial model. Obviously, they both match well.

Figure 10 shows the estimated $S$-wave velocity structures by the differential inversion technique at all 16 sites. Compared with the other sites, sites AIL, DAH and YUY have a higher $S$-wave velocity at depths of less than $200 \mathrm{~m}$. If the $S$-wave velocity of the bedrock in the Puli area is assumed to be $2000 \mathrm{~m} / \mathrm{s}$ (Wang et al., 2003), the depths of the Quaternary sediments are between $390 \mathrm{~m}$ (FAL) and $960 \mathrm{~m}$ (AIL).

On the basis of gradient changes in the velocity structure derived from the differential inversion (Fig. 10), we can regroup the layered structure. Therefore, the inverted structure with 80 layers is simpli ed to be a structure with fewer layers (e.g. 7 layers at the CUH site). Based on the simpli ed velocity models, we further use the stochastic inversion technique (Herrmann, 1991) to invert the $S$-wave velocity structures at all 16 sites, and the results are shown in Fig. 11. Apparently, there is a thicker layer with $S$ wave velocities ranging from 1400 to $1700 \mathrm{~m} / \mathrm{s}$ at sites AIL, DAH and YUY, whose relative thicknesses are about $600 \mathrm{~m}$ (AIL), $750 \mathrm{~m}$ (DAH), and $540 \mathrm{~m}$ (YUY), respectively. The results indeed re ect the phenomenon that we see in the dispersion curves (Fig. 7). If the $S$-wave velocity of bedrock is assumed to be $2000 \mathrm{~m} / \mathrm{s}$, the depths of the Quaternary sediments at the Puli area are between $300 \mathrm{~m}$ (FAL, PIP) and $870 \mathrm{~m}(\mathrm{DAH})$. There are 3 6 distinct interfaces in the shal- 


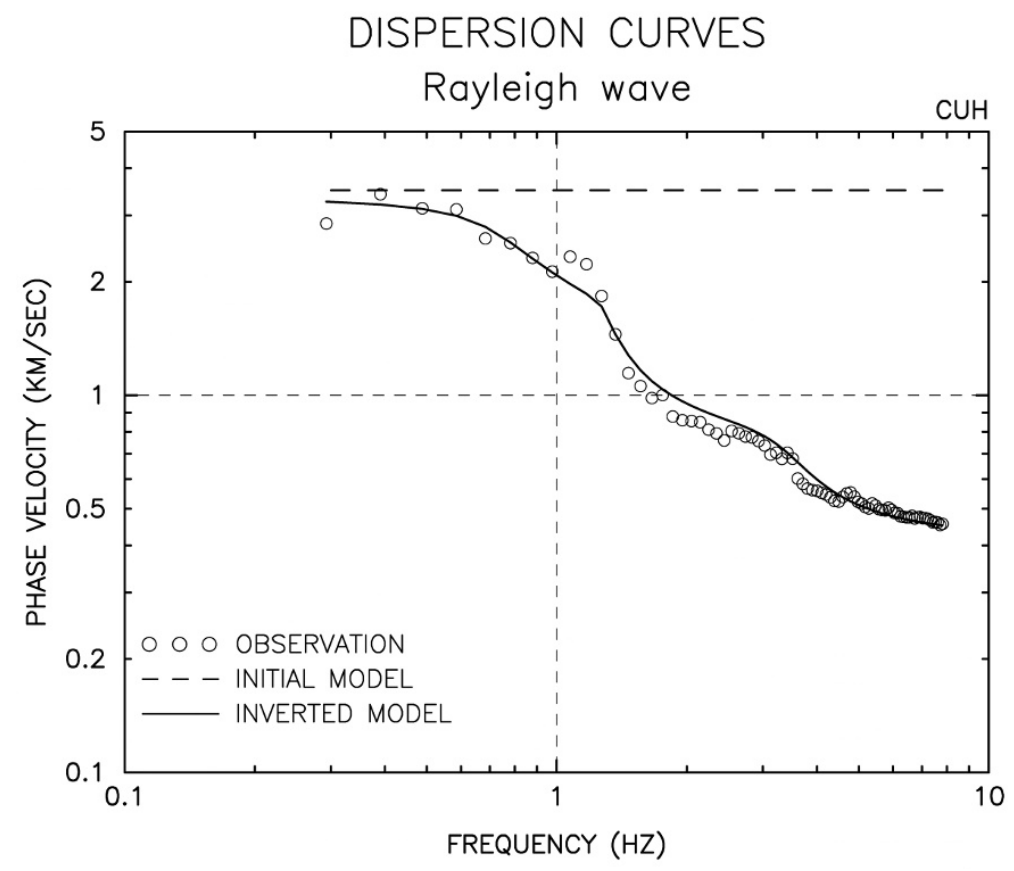

Fig. 9. Comparison between the observed phase velocities (open circles) and the theoretical phase velocities (solid line) of the fundamental mode of the Rayleigh wave for the nal inverted velocity structure. The dashed line represents the initial model for the inversion at site CUH.
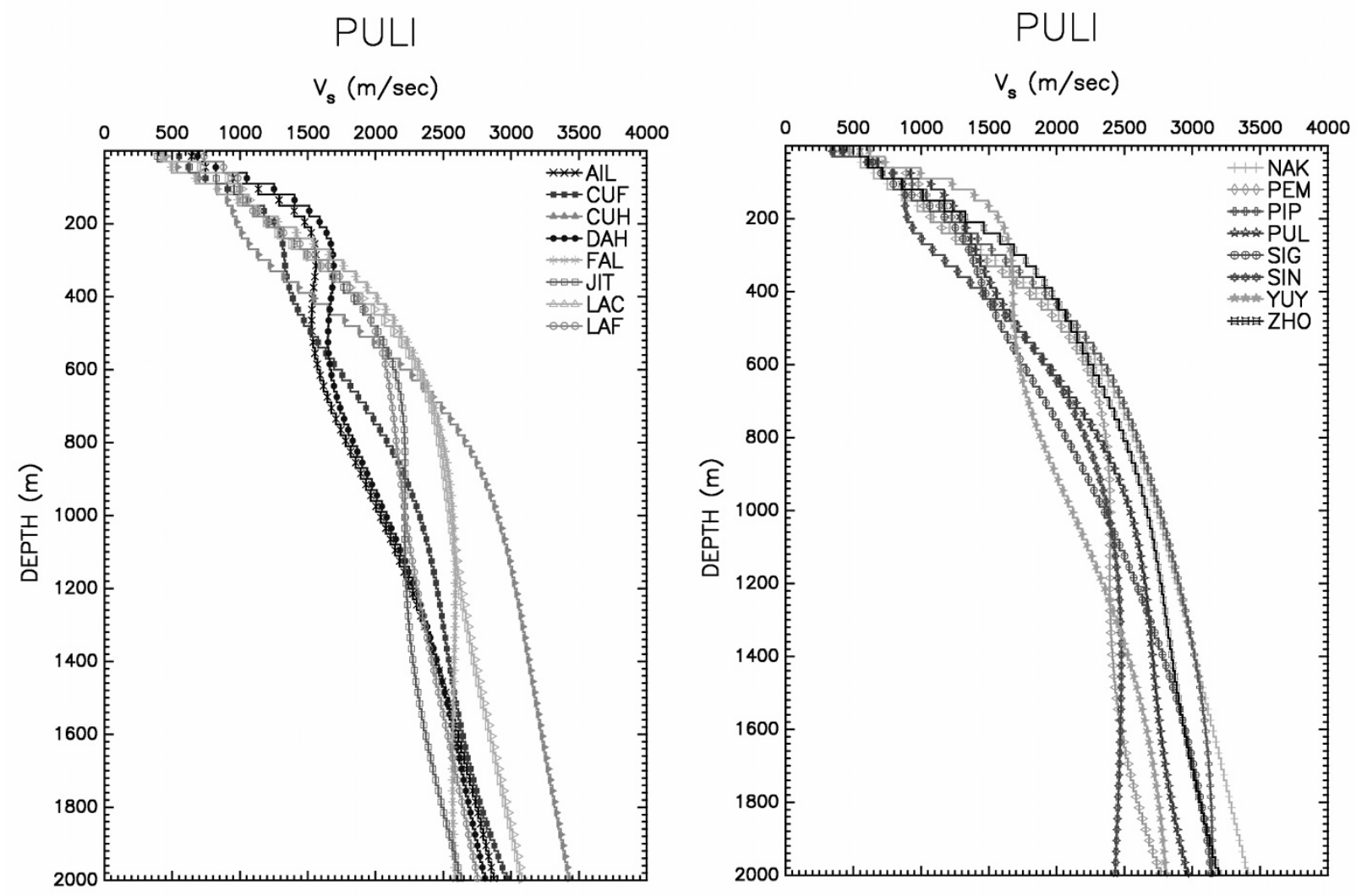

Fig. 10. Estimated $S$-wave velocity structures by the differential inversion technique (Herrmann, 1991) at all 16 sites. It is divided into two panels because the lines are too numerous for one gure.

low velocity structure $(0 \sim 1000 \mathrm{~m})$. The shallow $S$-wave velocity structures of the 16 sites of the Puli basin are listed in Table 2. Comparatively, velocity changes with different layers are smooth in the differential inverted results and this improves the discussion of lateral change to velocity structure. On the other hand, the obvious interfaces can be found in the stochastic inverted results, which are more suitable for ground motion simulation. 

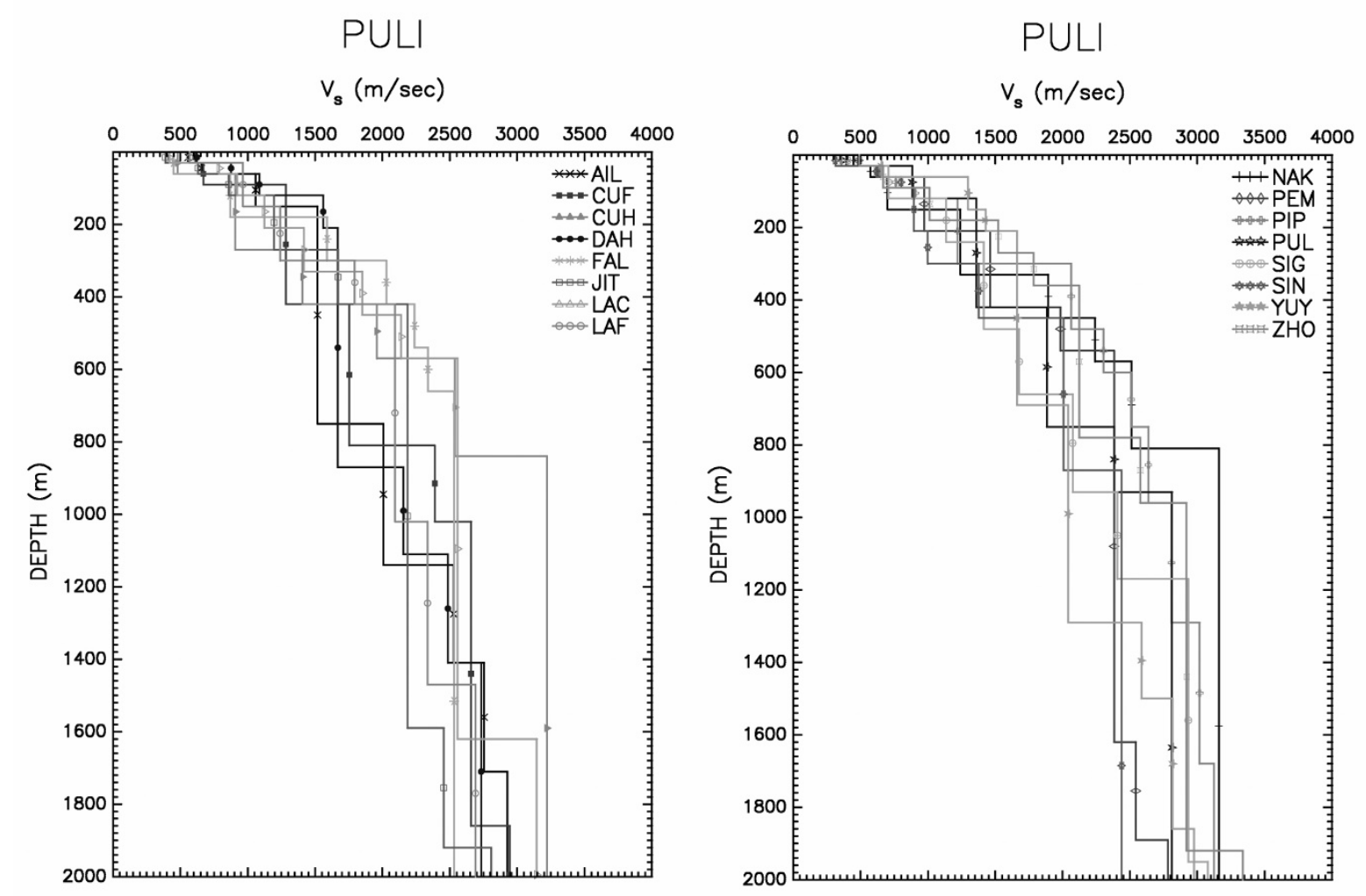

Fig. 11. Estimated $S$-wave velocity structures by the stochastic inversion technique (Herrmann, 1991) at all 16 sites. It is divided into two panels because the lines are too numerous for one gure.
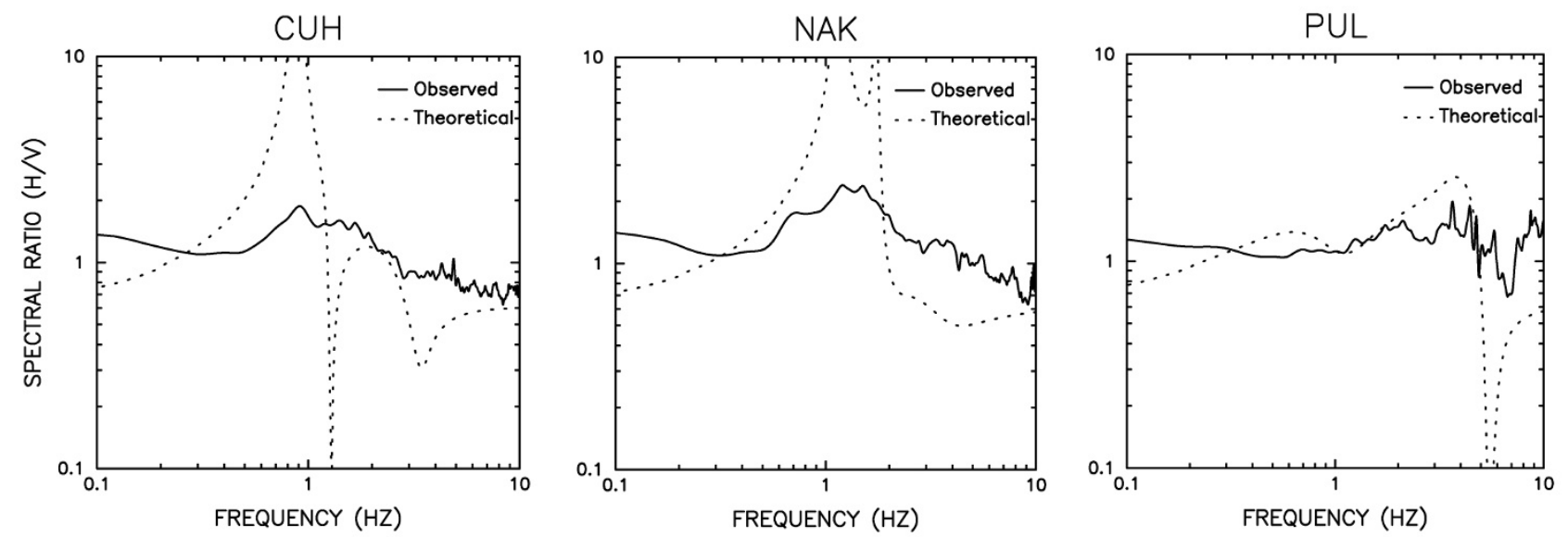

Fig. 12. Comparison between the observed $H / V$ ratios of microtremor data (solid lines) and the theoretical ones of the Rayleigh wave (or ellipticity, dotted lines) based on the inverted velocity models.

\subsection{Comparison of the $S$-wave velocity structures}

Based on the inverted velocity structures (Fig. 11), we calculate the ellipticity of the fundamental Rayleigh wave which also represents the theoretical $H / V$ ratio here. Figure 12 shows the comparison between the $H / V$ ratios (solid line) using the microtremor data and the theoretical $H / V$ ratios of the Rayleigh wave (or ellipticity, dotted line) based on the inverted velocity structures with no damping at three sites (CUH, NAK and PUL). Basically, there is a good match at the predominant frequency between these two results. However, the amplitude of the peaks and troughs from the theoretical $H / V$ result do not agree well with that of the observed data. The peak and trough of the theoretical $H / V$ ratio of the fundamental-mode Rayleigh wave is in nite because transitions from the prograde to the retrograde (or vice versa) will take place at the peak or trough. Besides, the amplitudes of the $H / V$ ratios of microtremors at the NAK site are larger than those at the CUH and PUL sites (between 0.5 and $3 \mathrm{~Hz}$ ). Based on the match of the predominant frequency, the inverted structure is reliable here.

Furthermore, in order to examine the validity of the shallow velocity structures by the microtremor array measurements, we compare our results with those from the seismic exploration method. Figure 13 shows the comparison be- 


\begin{tabular}{|c|c|c|c|c|c|c|c|}
\hline 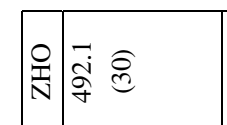 & : & 笠 & 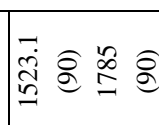 & 중 & 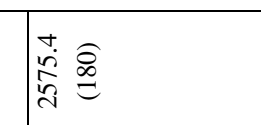 & 商高 & 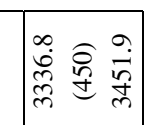 \\
\hline 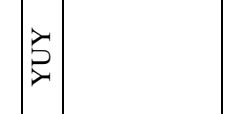 & 善高 & 总高 & 裙囟 & 熟产 & 䓲 & 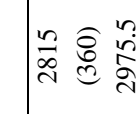 & \\
\hline 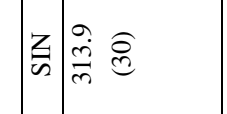 & 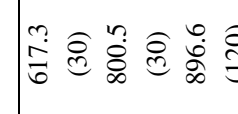 & 害高 & 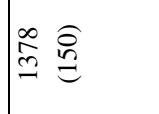 & 管 & 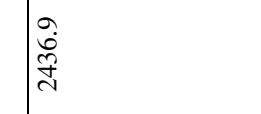 & & \\
\hline 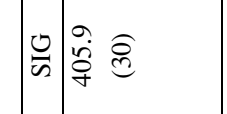 & 異 & 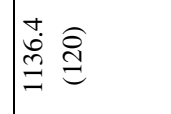 & 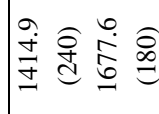 & 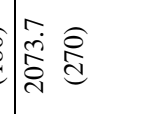 & 象拿 & 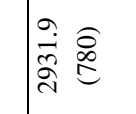 & 兽 \\
\hline 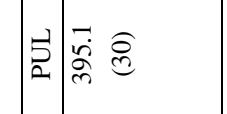 & 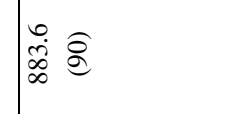 & 㞔高 & & 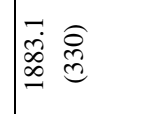 & 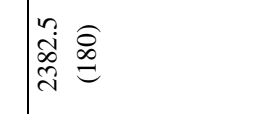 & 辛总 & $\vec{p}$ \\
\hline 高窝递 & 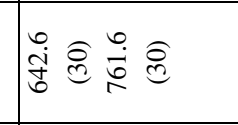 & 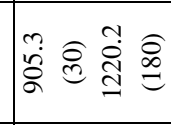 & & 递晜 & 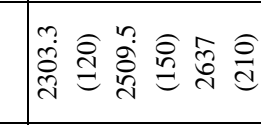 & 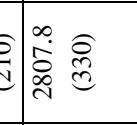 & 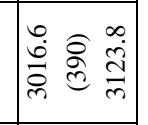 \\
\hline 㗜誉启 & 象 & 商商 & 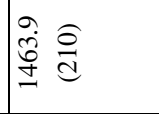 & 程高 & 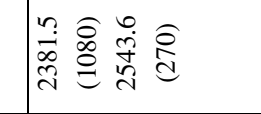 & 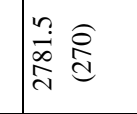 & 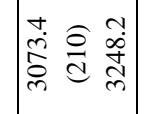 \\
\hline 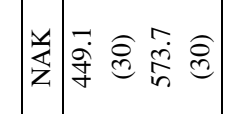 & 唐重 & 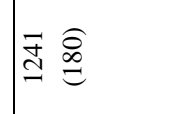 & & 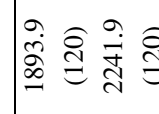 & 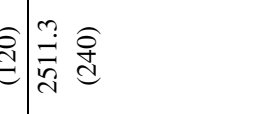 & & 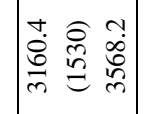 \\
\hline 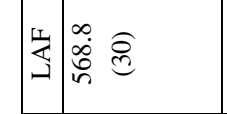 & & 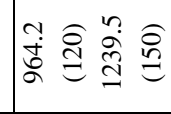 & 等 & 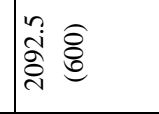 & 拿善高 & 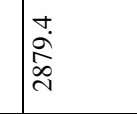 & \\
\hline$\frac{0}{3} \frac{\alpha}{q}$ & $\begin{array}{l}\infty \\
\infty \\
\infty \\
\infty\end{array}$ & 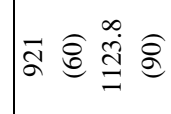 & 筀送 & 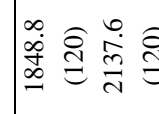 & 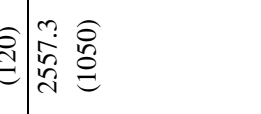 & & 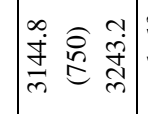 \\
\hline 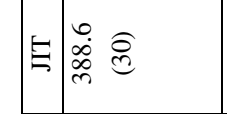 & 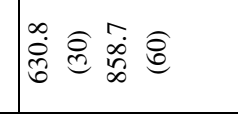 & 尊䔡 & 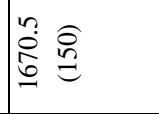 & 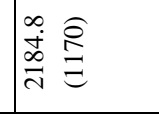 & 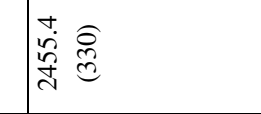 & 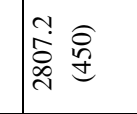 & 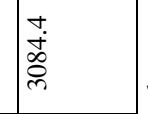 \\
\hline 素章高 & : & & 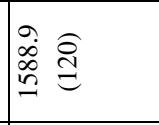 & 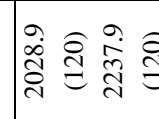 & 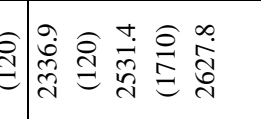 & & \\
\hline 咅 & لुं & 商 & 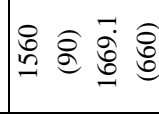 & 票题 & 管 & 旅 & \\
\hline 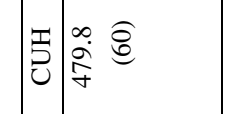 & & 高 & 鉒余 & 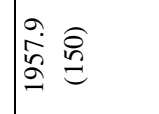 & 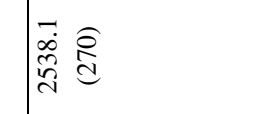 & & 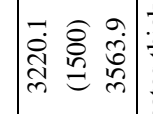 \\
\hline 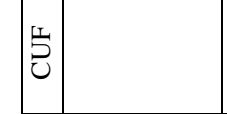 & 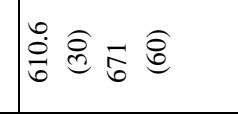 & 邆递 & 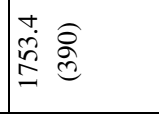 & & 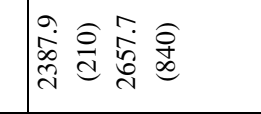 & 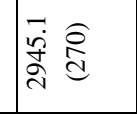 & 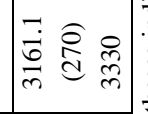 \\
\hline 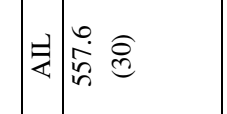 & 呞递 & 蒙金 & 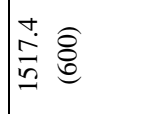 & 商 居 & त्र̃ & 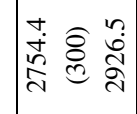 & \\
\hline - & 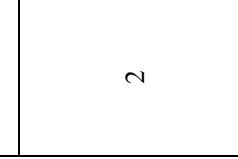 & $m$ & + & $n$ & 0 & - & $\infty$ \\
\hline
\end{tabular}


(a)

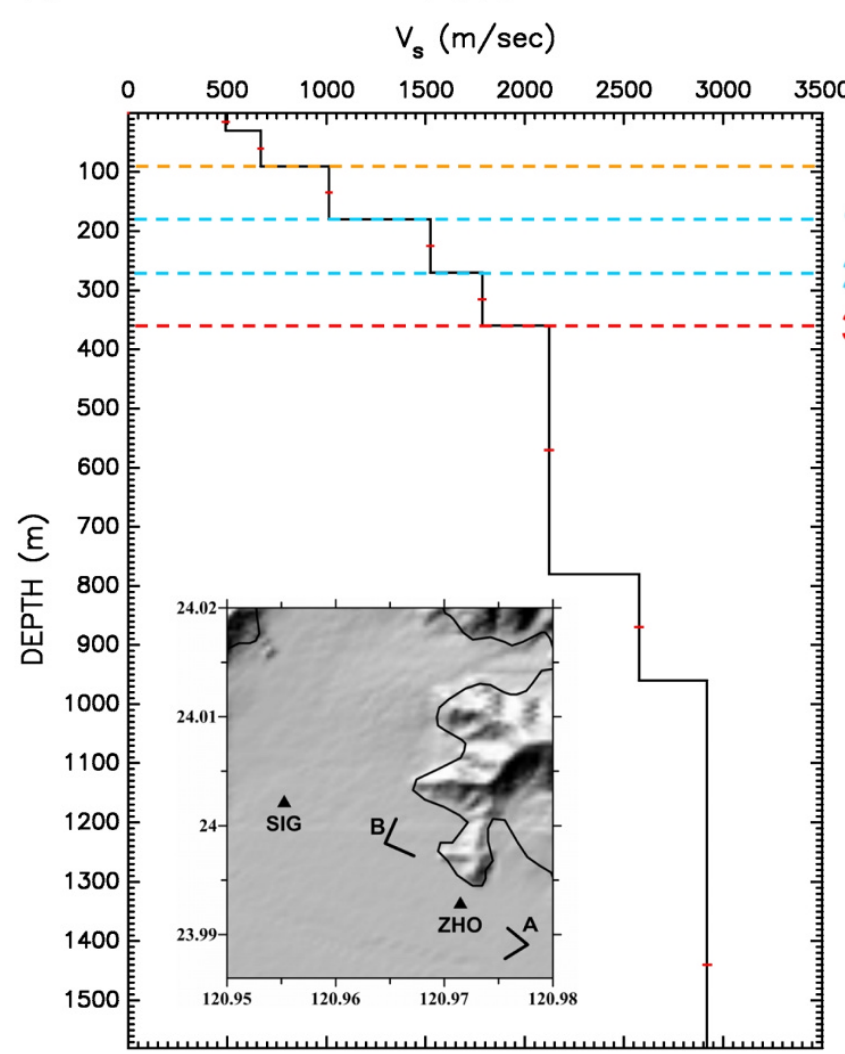

(b)

B

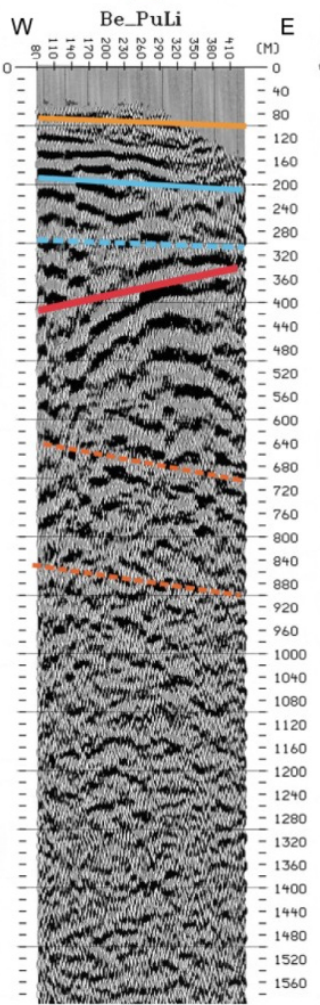

A

W Ae_PuLi SE

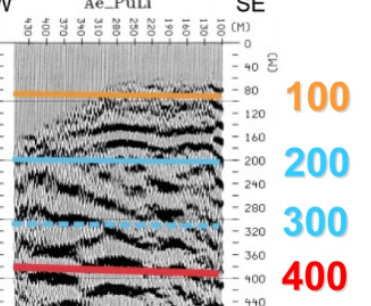

Fig. 13. (a) Estimated $S$-wave velocity structure using the stochastic inversion technique at site ZHO. The small inset map shows the locations of ZHO, A and B sites. (b) Seismic reflection profiles at the A and B sites which are close to the ZHO site (Huang, 2008).

(a)

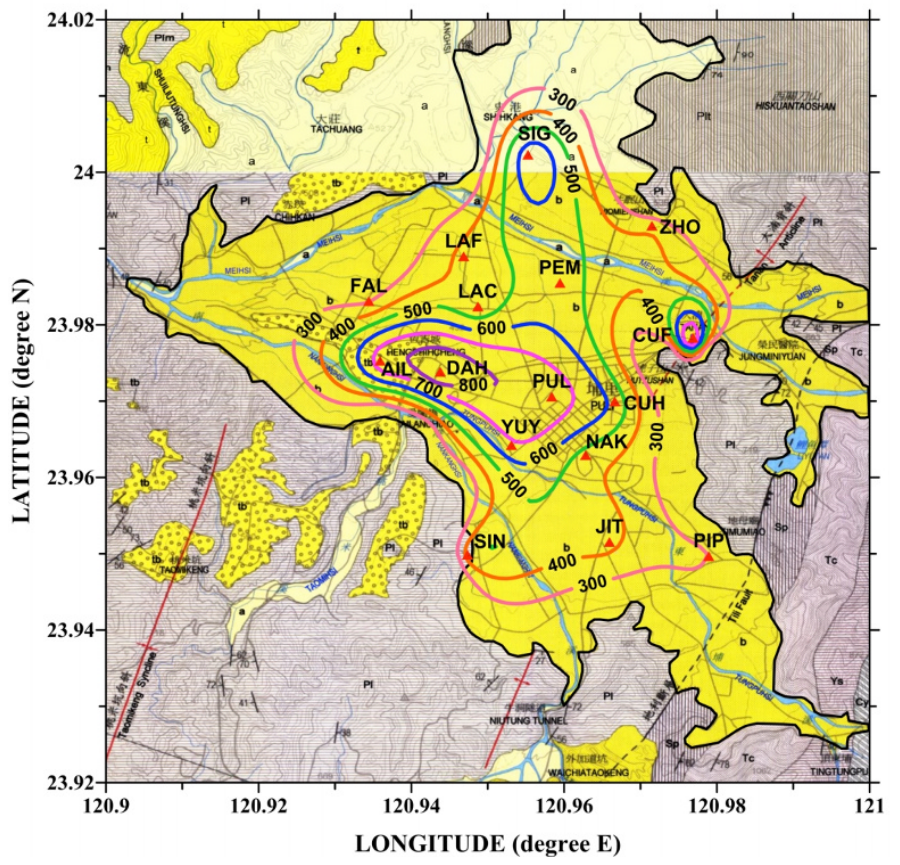

(b)

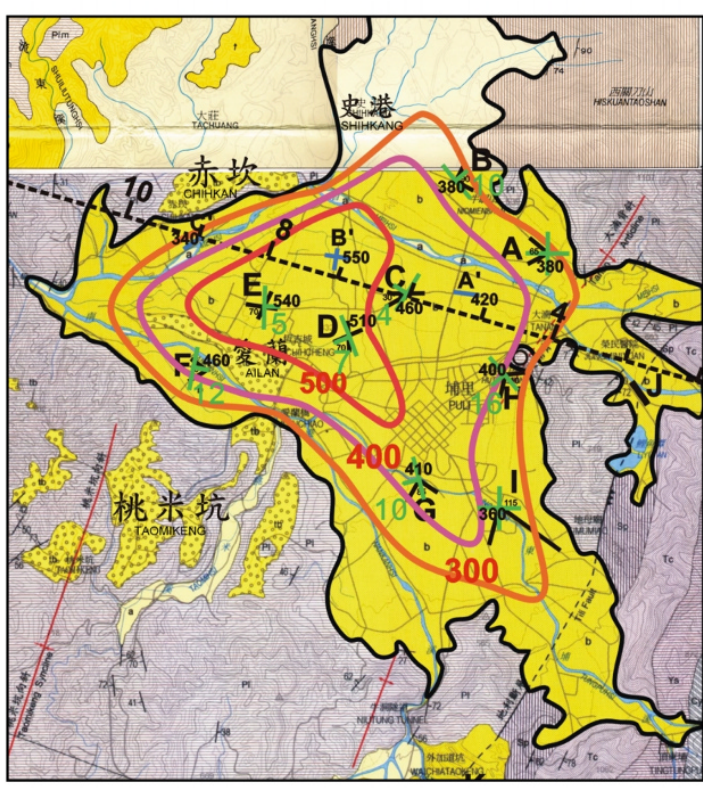

Fig. 14. (a) Based on Fig. 10, the variations of the depths of the bedrock $\left(V_{S}=2000 \mathrm{~m} / \mathrm{s}\right.$ ) are between $300 \mathrm{~m}$ and $870 \mathrm{~m}$ in the Puli basin. (b) Map sketching the variations in depth of the bedrock obtained by the seismic reflection method in the Puli basin (Huang, 2008). 
tween the shallow $S$-wave velocity structure at site $\mathrm{ZHO}$ with those from the seismic re ection method at the A, B sites (Huang, 2008). According to Huang's study, four obvious interfaces exist at the near surface and their depths are 100, 200, 300 and $400 \mathrm{~m}$ while these depths are 90, 180, 270 and $360 \mathrm{~m}$, respectively from our inverted result. The average $S$-wave velocity of the sediments is about $1030 \mathrm{~m} / \mathrm{s}$ at the ZHO site from the study, while this is about $950 \mathrm{~m} / \mathrm{s}$ from the seismic re ection method. Hence, both results are similar.

Besides this, we also compare the depth distribution of the bedrock (assuming $V_{S}=2000 \mathrm{~m} / \mathrm{s}$ ) between our results (left panel) based on Fig. 11 with those (right panel) from the seismic re ection method (Huang, 2008) in the Puli basin, as shown in Fig. 14. The black dashed line crossing the basin in Fig. 14(b) denotes the survey line (total distance about $12 \mathrm{~km}$ ) of the explosion experiments by Wang et al. (2003). After that, they carried out shallow seismic re ection surveys at three sites $\left(\mathrm{A}^{\prime}, \mathrm{B}^{\prime}\right.$ and $\left.\mathrm{C}^{\prime}\right)$ near the survey line. In order to sketch the depth variations of the Tertiary basement beneath the basin, Huang (2008) used the shallow seismic re ection method at nine sites (from A to I in Fig. 14(b)). Finally, he combined the results with those from Wang et al. (2003) and proposed a contour map of the bedrock depths in the Puli basin (Fig. 14(b)).

In the Puli basin, the depths of the bedrocks are about 300 870 $\mathrm{m}$ by the microtremor array measurements (Fig. 14(a)) while these are about 300 600 $\mathrm{m}$ by Huang (2008) (Fig. 14(b)). The depth of the bedrock is deeper in the central part (e.g. PUL, DAH) of the basin while it is relatively shallower at the edges (e.g. SIN, PIP). The depth of the bedrock gradually increases from the edge to the center of the basin and the deepest area is near Heng-Chih-Cheng (DAH). Moreover, some sites (SIG and CUF) with deeper bedrocks are found in the northern and eastern parts using the microtremor array measurements (Fig. 14(a)). We deploy three sites (CUH, NAK and PUL) at the downtown area while the explosion experiment is not easy to survey (Huang, 2008; Fig. 14(b)). According to the inverted results, we can get the detailed $S$-wave velocity structures in the study. However, the explosion experiments can clearly describe the stratum and attitude of stratum (e.g. Fig. 13(b)). Overall, the results from microtremor array measurements and from Huang (2008), regarding the bedrock depths, present similar patterns though there are some differences in detail. The possible reasons causing the discrepancies between these results are due to the differences of the measured sites, the measurement methods and the techniques of data processing used.

\section{Conclusions}

The aim of this study was to estimate the $S$-wave velocity structure of the Puli basin using microtremor array measurements. The measurements were carried out with 64 different size arrays whose radii range from 50 to $400 \mathrm{~m}$ at 16 sites. Based on the results of the propagation direction estimated from the $f-k$ spectra, we nd that the microtremor wave eld at the higher frequencies is dominated by anthropogenic sources in the Puli basin. At frequencies lower than about $0.66 \mathrm{~Hz}$, the propagation directions concentrate in the northwest and west quadrants, coinciding with the direction of the Taiwan Strait coast line.

We can, however, estimate the phase velocity from the frequency and the wavenumber of the maximum peak in the $f-k$ spectrum. The estimated phase velocities at the 16 sites vary from site to site. The derived dispersion curves indicate that sites AIL, DAH and YUY have higher phase velocities while frequencies are greater than $3 \mathrm{~Hz}$, however, at frequencies between 1.0 and $2.7 \mathrm{~Hz}$, the phase velocities become at at $1.3-1.5 \mathrm{~km} / \mathrm{s}$. The results from the stochastic inversion technique (Herrmann, 1991) show that the thicknesses of the Quaternary sediments are between $300 \mathrm{~m}$ and $870 \mathrm{~m}$ in the Puli basin, if the $S$-wave velocity of the bedrock is assumed to be $2000 \mathrm{~m} / \mathrm{s}$. Also, the shallow velocity structure $(0 \sim 1000 \mathrm{~m})$ can be roughly divided into 3-6 layers.

To validate the $S$-wave velocity structures obtained from the microtremor array measurements, theoretical $H / V$ ratios based on the velocity model were compared with the $H / V$ ratios of microtremor data at three sites. The results show good agreement at the predominant frequencies; however, both the peak and trough amplitudes between the simulated results and observational results do not match well. We also compare our results with those from seismic exploration calculations conducted by other researchers and nd the patterns are similar overall although there are some discrepancies in the detail. Both patterns indicate the depth of the bedrock gradually increasing from the basin's edge to its center.

Acknowledgments. The authors would like to express their gratitude to Drs. R. D. Hwang and W. G. Huang for providing the programs and for their stimulating discussions. The authors appreciate the efforts of the Engineering Seismology Laboratory of NCCU, which provided microtremor measurements in the eld. They also wish to thank Drs. E. D. Pezzo and H. Kawase for their valuable comments and suggestions to improve this paper. The National Science Council, Taiwan has supported this research (NSC 97-2745-M-194-002).

\section{References}

Arai, H. and K. Tokimatsu, Effects of Rayleigh and Love waves on microtremor H/V spectra, Proc. 12th World Conf. Earthq. Eng., Auckland, New Zealand, January 30-February 4, paper 2232, 2000.

Capon, J., High-resolution frequency-wavenumber spectral analysis, Proc. IEEE, 57, 1408-1418, 1969.

Di Giulio, G., C. Cornou, M. Ohrnberger, M. Wathelet, and A. Rovelli, Deriving wave eld characteristics and shear-velocity pro les from twodimensional small-aperture arrays analysis of ambient vibrations in a small-size alluvial basin, Col orito, Italy, Bull. Seismol. Soc. Am., 96, 1915-1933, 2006.

Herrmann, R. B., Computer Program in Seismology, Saint Louis University, St. Louis, Missouri, 1991.

Horike, M., Inversion of phase velocity of long-period microtremors to the $\mathrm{S}$-wave-velocity structure down to the basement in urbanized area, $J$. Phys. Earth, 33, 59-96, 1985.

Huang, C. C., Shallow Seismic Re ection Study in the Puli Basin, Master thesis, National Central University, Taiwan, 2008 (in Chinese with English abstract).

Huang, C. S., K. S. Shea, and M. M. Chen, Explanatory Text of the Geological Map of Taiwan (Pu-Li, scale 1:50,000, sheet 32), Central Geology Survey, the Ministry of Economic Affairs, Taiwan, 2000 (in Chinese with English abstract).

Huang, H. C. and C. R. Tarng, Site characteristics of the Puli area, Taiwan, TAO, 16, 467-485, 2005.

Huang, H. C. and C. F. Wu, Estimation of S-wave velocity structures in the Chia-Yi City, Taiwan using array records of Microtremors, Earth 
Planets Space, 58, 1455-1462, 2006.

Hwang, R. D. and G. K. Yu, Shear-wave velocity structure of upper mantle under Taiwan from the array analysis of surface waves, Geophys. Res. Lett., 32, L07310, 2005.

Kind, F., D. Fäh, and D. Giardini, Array measurements of S-wave velocities from ambient vibrations, Geophys. J. Int., 160, 114-126, 2005.

Maresca, R., D. Galluzzo, and E. Del Pezzo, H/V spectral ratios and array techniques applied to ambient noise recorded in the Col orito Basin, Central Italy, Bull. Seismol. Soc. Am., 96, 490-505, 2006.

Matsushima, T. and H. Okada, Determination of deep geological structures under urban areas using long-period microtremors, Butsuri-Tansa, $\mathbf{4 3}$, 21-33, 1990.

Menke, W., Geophysical Data Analysis: Discrete Inversion Theory, Elsevier, New York, 1984.

Satoh, T., H. Kawase, and S. Matsushima, Estimation of S-wave velocity structures in and around the Sendai basin, Japan, using array records of microtremors, Bull. Seismol. Soc. Am., 91, 206-218, 2001a.

Satoh, T., H. Kawase, T. Iwata, S. Higashi, T. Sato, K. Irikura, and H. C. Huang, S-wave velocity structure of the Taichung basin, Taiwan, estimated from array and single-station records of microtremors, Bull. Seismol. Soc. Am., 91, 1267-1282, 2001b.

Site EffectS assessment using AMbient Excitations (SESAME), http://sesame-fp5.obs.ujf-grenoble.fr, 2001-2004.

Wang, C. Y., B. S. Huang, H. Y. Yen, Y. B. Tsai, and K. L. Wen, Puli Explosion Experiment, in Proceedings of the 10th Symposium of Geophysical Research in Taiwan, pp. 19-25, Chiayi, Taiwan, October 16-17, 2003 (in Chinese).

C.-F. Wu and H.-C. Huang (e-mail: seihuey@eq.ccu.edu.tw) 